\title{
TEOR DE AÇÚCARES SOLÚVEIS E INSOLÚVEIS EM FOLHAS DE VIDEIRAS, cv. SYRAH, EM DIFERENTES POSIÇÕES NO RAMO E ÉPOCAS DO ANO. ${ }^{1}$
}

\author{
BÁRBARA FRANÇA DANTAS², LUCIANA DE SÁ RIBEIRO ${ }^{3}$, MAIANE SANTOS PEREIRA $^{4}$
}

RESUMO- Com o crescimento da área cultivada de videira para produção de vinho, tem aumentado a demanda por pesquisas para a região semi-árida do Brasil que resultem no desenvolvimento da viticultura no Vale do São Francisco. Todos os produtos da videira, como uva, vinho, passas, vinagre, têm origem nos açúcares que são produzidos nas folhas durante a fotossíntese e transportados, tanto para os frutos, na época de produção, como para troncos, raízes, folhas não expandidas na fase vegetativa. O objetivo deste trabalho é avaliar a influência da posição no ramo e da variação sazonal no teor de açúcares solúveis e insolúveis nas folhas em videiras para vinho (Vitis vinifera L.), cv. Syrah, no Vale do São Francisco. Para tanto, o trabalho foi realizado em um vinhedo comercial e no Laboratório de Sementes/ Fisiologia Vegetal da Embrapa Semi-Árido. A partir dos resultados observados, conclui-se que os açúcares são produzidos em maior quantidade, a partir da quinta folha expandida e acumulam-se em folhas próximas aos cachos. $\mathrm{O}$ acúmulo de açúcares nas folhas aumenta após o início da maturação; no entanto, é fortemente influenciado pela temperatura, insolação e radiação.

Termos para indexação: Vitis vinifera, fenologia, carboidratos.

\section{SOLUBLE AND INSOLUBLE SUGARS CONTENT IN CV. SYRAH GRAPEVINE LEAVES IN DIFFERENT POSITIONS OF THE BRANCH AND SEASONS}

\begin{abstract}
Due to the growth of grapevines cultivated areas for wine production, the requirement for viticulture researches have increased for the Brazilian semi-arid region, that could result in a great development of the viticulture at São Francisco River Valley. All commercialized products of the grapevine, as grape, wine, raisin, vinegar, have their origin in the sugars which are produced in leaves during photosynthesis and transported, in production time, to fruits, trunks, roots and leaves which do not expand in vegetative phase. The objective of this work was to evaluate the influence of the branch position and the seasonal variations in the content of soluble and insoluble sugars in 'Syrah' grapevine for wine production, cultivated at São Francisco River Valley. This work was carried out in a commercial vineyard and at the Seed/ Plant Physiology laboratory of Embrapa Semi-Arid, Petrolina- Pernambuco State, Brazil. The results allowed to conclude that the sugars are produced in higher quantities, starting from the fifth expanded leaf and are accumulated in leaves next to the bunches. The sugars content in the leaves opposite to the bunches increases during the grape maturation. However, it is strongly influenced by temperature, insolation and radiation.
\end{abstract}

Index terms: Vitis vinifera, phenology, carbohydrates

\section{INTRODUÇÃO}

Tecidos fotossinteticamente ativos, como folhas maduras, produzem mais carboidratos do que as mesmas necessitam para manterem seu metabolismo e crescimento, exportando os fotoassimilados excedentes, na forma de sacarose, para tecidos fotossinteticamente menos ativos ou inativos, como folhas jovens, raízes, cachos ou ramos. No entanto, as relações fontedreno não são estáticas. Durante o crescimento vegetativo, a maioria dos carboidratos é transportada para as raízes e folhas jovens, enquanto, após o florescimento, os carboidratos são direcionados prioritariamente para os frutos, tubérculos e raízes de reserva (Roitsch et al., 2003).

De acordo com Hunter et al. (1994) e Palliotti \& Cartechini (2001), os teores de glicose, frutose e sacarose, bem como a atividade de enzimas do metabolismo de carboidratos em folhas de videiras (Vitis vinifera L.), são influenciados por variações sazonais e fenológicas. Tanto a expressão gênica, quanto a atividade das invertases são influenciadas por uma variedade de fatores intra e extracelulares (Tymowska-Lalanne \& Kreis, 1998), como estímulos ambientais, estímulos hormonais e fases fenológicas (Roitsch et al., 2000; 2003).

O Pólo Vitivinícola do Vale do Rio São Francisco, localizado entre os paralelos de latitude $9^{\circ}$ e $10^{\circ}$ sul, é a única região produtora de vinho que possui um clima semi-árido tropical, classificado como "BSh" de acordo com Köeppen (Teixeira, 2001). Assim, a produção de uvas para vinho nesse clima, em que a temperatura está sempre acima de $12^{\circ} \mathrm{C}$ e são possíveis até 2,5 colheitas por ano, é completamente diferente de outras regiões produtoras de vinho.

De acordo com Pommer \& Passos (2005), todas as formas de produtos de videira têm origem nos açúcares produzidos nas folhas, através da fotossíntese, e transportados tanto para os frutos, na época de produção, como para troncos, raízes e folhas não expandidas na fase vegetativa. Não existem, no entanto, informações a respeito do acúmulo de carboidratos em folhas de

\footnotetext{
${ }^{1}$ (Trabalho 081-2006). Recebido em 08-06-2006. Aceito para publicação em 06-02-2007. Trabalho realizado com suporte do Banco do Nordeste, FACEPE/CNPq e FAGRO

${ }^{2}$ Pesquisadora, Embrapa Semi-Árido, CP23, CEP56302-970, Petrolina-PE. (87)38621711. barbara@cpatsa.embrapa.br

${ }^{3}$ Bióloga, Estagiária, Embrapa Semi-Árido Petrolina - PE;

${ }^{4}$ Bióloga, Mestranda em Fisiologia Vegetal, Universidade Estadual do Norte Fluminense "Darci Ribeiro", Campos dos Goytacazes- RJ.
} 
videira no ambiente da região do Vale do São Francisco. A obtenção dessas informações durante o ciclo da cultura poderá contribuir para diagnosticar o estado de vigor fisiológico no qual a planta se encontra.

O objetivo deste estudo é avaliar a influência da posição no ramo e da variação sazonal no teor de açúcares solúveis e insolúveis nas folhas de Vitis vinifera L., cv. Syrah, durante quatro ciclos de produção consecutivos, nos anos de 2003 e 2004.

\section{MATERIAL E MÉTODOS}

O experimento foi conduzido no Laboratório de Sementes/ Fisiologia Vegetal da Embrapa Semi-Árido, Petrolina-PE, e em um vinhedo comercial de 4,13ha, localizado no município de Lagoa Grande-PE, cultivado com videiras cv. Syrah, enxertadas sobre o porta-enxerto IAC572, com dez anos de idade, conduzidas no sistema de espaldeira, em Latossolo Vermelho-Amarelo, num espaçamento de $1,20 \mathrm{~m} \times 3,5 \mathrm{~m}$ e irrigadas por gotejamento. Foram coletadas folhas de várias posições do ramo de quatro videiras (quatro repetições), em um delineamento inteiramente casualisado, logo após a colheita do ciclo produtivo do segundo semestre de 2002. Durante os quatro ciclos produtivos subseqüentes, durante os anos de 2003 e 2004, a partir do início da floração, foram coletadas, semanalmente, folhas opostas aos cachos. As amostras foram congeladas em freezer a $-20^{\circ} \mathrm{C}$ até a realização das análises bioquímicas.

A extração de açúcares redutores (AR) e açúcares solúveis totais (AST) foi realizada em água destilada (Dantas \& Ribeiro, 2005; Dantas et al., 2005), e o precipitado foi utilizado para a extração de amido em ácido perclórico $\left(\mathrm{HClO}_{4}\right) 52 \%$ (Allen et al., 1977). A quantificação dos teores de $A R$ e de amido foi realizada conforme metodologia descrita por Miller (1959), e os teores de AR foram quantificados de acordo com Morris (1948) e Yemm \& Willis (1954).

\section{RESULTADOS E DISCUSSÃO}

Pode-se observar, na Figura 1a, que houve grande aumento no teor foliar de açúcares redutores (AR) durante os primeiros estágios de desenvolvimento da folha. As folhas mais novas, em expansão e sem o aparato fotossintético completamente desenvolvido, apresentaram baixo teor de AR, sendo 4,32mmol por gramas de matéria fresca (MF). O teor de AR aumentou gradativamente até a $5^{\text {a }}$ folha do ramo: esta é a primeira folha completamente expandida e com o aparato fotossintético plenamente desenvolvido; a partir de então, há uma pequena queda no teor de AR, que se mantém em torno de $65 \mathrm{mmol.g}{ }^{-1} \mathrm{MF}$ até a $13^{\text {a }}$ folha no ramo. Da posição 15 à posição 23 , folhas mais próximas ao cacho, que se encontrava oposto à $18^{\mathrm{a}}$ folha, podem ser observadas em outro patamar com um teor foliar de AR em torno de $85 \mathrm{mmol} . \mathrm{g}^{-1} \mathrm{MF}$, aumentando para $95 \mathrm{mmol.g} \mathrm{g}^{-1} \mathrm{MF}$ na posição seguinte. A partir deste estágio, as folhas iniciam o processo de senescência, e a taxa de fotossíntese cai, diminuindo o teor de AR nas folhas.

Da mesma forma que ocorre com o teor de AR, o teor de açúcares solúveis totais (AST) das folhas mais jovens é baixo, aumentando a partir da $5^{\text {a }}$ folha. Os teores foliares de AST se mantêm constantes, em torno de $10 \mathrm{mg} . \mathrm{g}^{-1} \mathrm{MF}$, até a folha anterior ao cacho, onde há um pico no teor de AST, chegando a $20 \mathrm{mg} . \mathrm{g}^{-}$ ${ }^{1} \mathrm{MF}$, reduzindo ao teor anterior nas posições seguintes (Figura $1 b)$.

O teor de amido (Figura 1c) das folhas mais jovens é baixo $\left(1,85 \mathrm{mg} \cdot \mathrm{g}^{-1} \mathrm{MF}\right)$, à semelhança do que ocorre com AR e AST, aumentando $60 \%$ a partir da $5^{\text {a }}$ folha. Na folha posteior ao cacho (posição 19), observa-se um pico no teor de amido $\left(12,16 \mathrm{mg} \cdot \mathrm{g}^{-1} \mathrm{MF}\right)$.

Folhas jovens em expansão mostram uma curva de crescimento sigmoidal, sendo que a máxima capacidade fotossintética das folhas ocorre quando estas atingem seu tamanho máximo. $\mathrm{O}$ aumento da atividade fotossintética e, conseqüentemente, do acúmulo de açúcares das folhas em expansão ocorre devido ao aumento do teor de clorofila por unidade de área foliar, ao aumento da atividade de enzimas carboxilativas e à diminuição da resistência estomática (Kliewer, 1981). Durante a maturação, os cachos são os drenos principais (Kliewer, 1981). Sendo assim, todos os açúcares produzidos pelas folhas são translocados para as bagas prioritariamente em relação aos meristemas apicais, acumulando AST e amido nas folhas próximas ao cacho (Figura 1b, c).

Entre os teores foliares de açúcares, o teor de AR apresentou correlação positiva com a temperatura mínima, para o ciclo 1. As demais variáveis do metabolismo de carboidratos (CHO) não apresentaram correlação significativa com variáveis climáticas (Tabela 1). Para o ciclo 2, a insolação apresentou correlação positiva com os teores de amido e AST. Estes se correlacionaram, também, com temperaturas (Tabela 1).

Nos ciclos 3 e 4, todas as variáveis do metabolismo de CHO se correlacionaram positivamente com o número de DAP, aumentando ao longo do ciclo produtivo. Os teores foliares de AST e amido se correlacionaram positivamente com a isolação nesse período (Tabela 2).

Na Tabela 3, pode-se observar o número de dias após a poda (DAP) e a duração, em dias, de cada fase fenológica (DFF) para os quatro ciclos estudados. Verifica-se que, exceto para o ciclo 2, a duração do ciclo produtivo, da poda até a colheita, de videiras 'Syrah' é de aproximadamente 120 dias. O ciclo 2, durante o $2^{\circ}$ semestre de 2003, foi estendido até 145 dias, devido ao baixo teor de sólidos solúveis totais (SST) ao redor de 120 dias, assim os cachos foram colhidos sobremaduros, conhecido regionalmente como "ponto de passa", mas com alto SST $\left(21,8^{\circ} \mathrm{C}\right)$ aos 147 DAP. O pintor, que é o início da maturação, observado pelo início da pigmentação das bagas, ocorre aos 78; 89; 111 e 102 DAP para os ciclos $1 ; 2 ; 3$ e 4, respectivamente.

Existe uma diferença notável na duração das fases iniciais e finais dos ciclos entre o primeiro e segundo semestres do ano. As fases iniciais durante o $1^{\circ}$ semestre são mais rápidas que durante o $2^{\circ}$ semestre do ano, sendo de 29 e 28 dias da poda até florescimento, para os ciclos 1 e 3 , e de 43 e 32 dias para os ciclos 2 e 4 , respectivamente. Por outro lado, as fases finais dos ciclos requerem menos dias no segundo semestre do ano, apresentando em média 85,5 e 75,5 dias da frutificação até a colheita para o $1^{\circ} \mathrm{e}$ $2^{\circ}$ semestres, respectivamente (Tabela 3 ). Isso, provavelmente, 


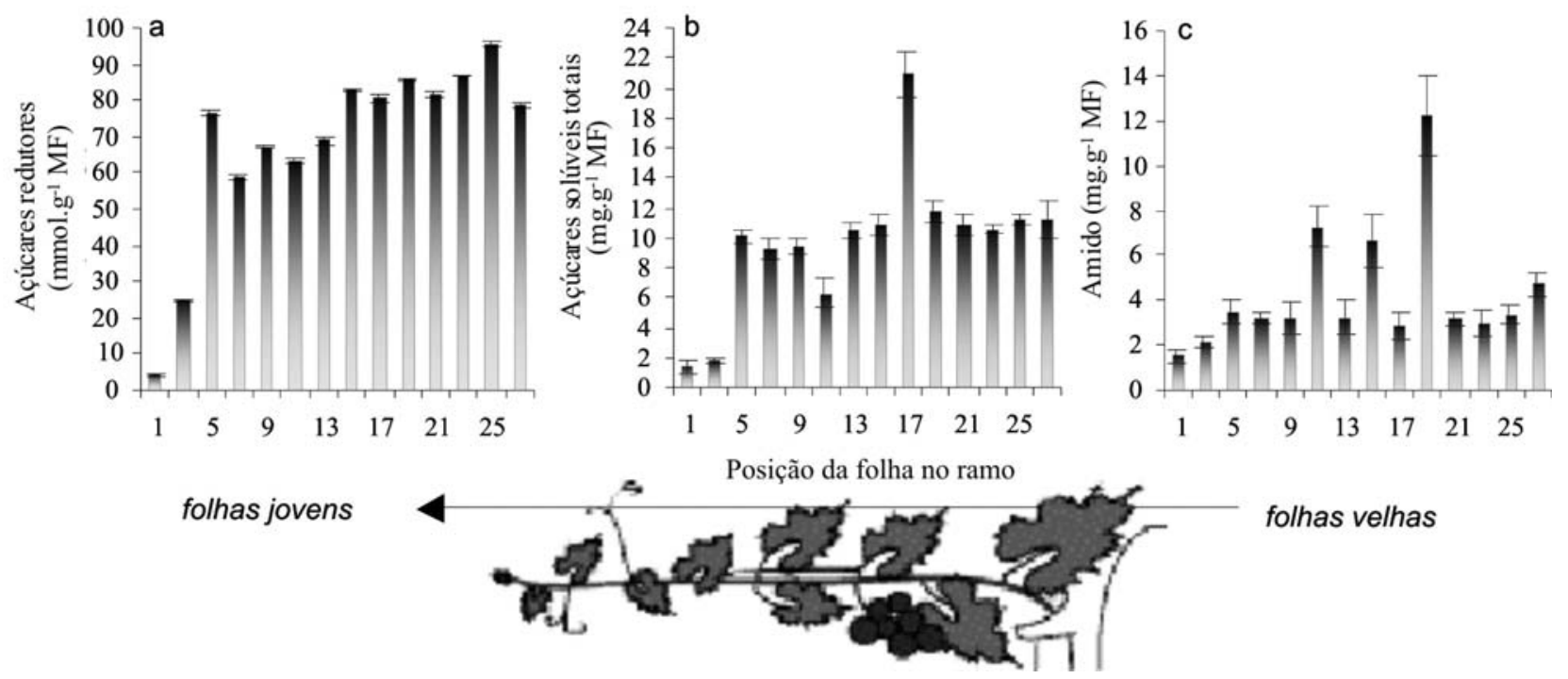

FIGURA 1 - Teor de açúcares redutores (a), açúcares solúveis totais (b) e amido (c) de folhas em diferentes posições no ramo de videiras 'Syrah'. As barras verticais correspondem ao erro- padrão da média.
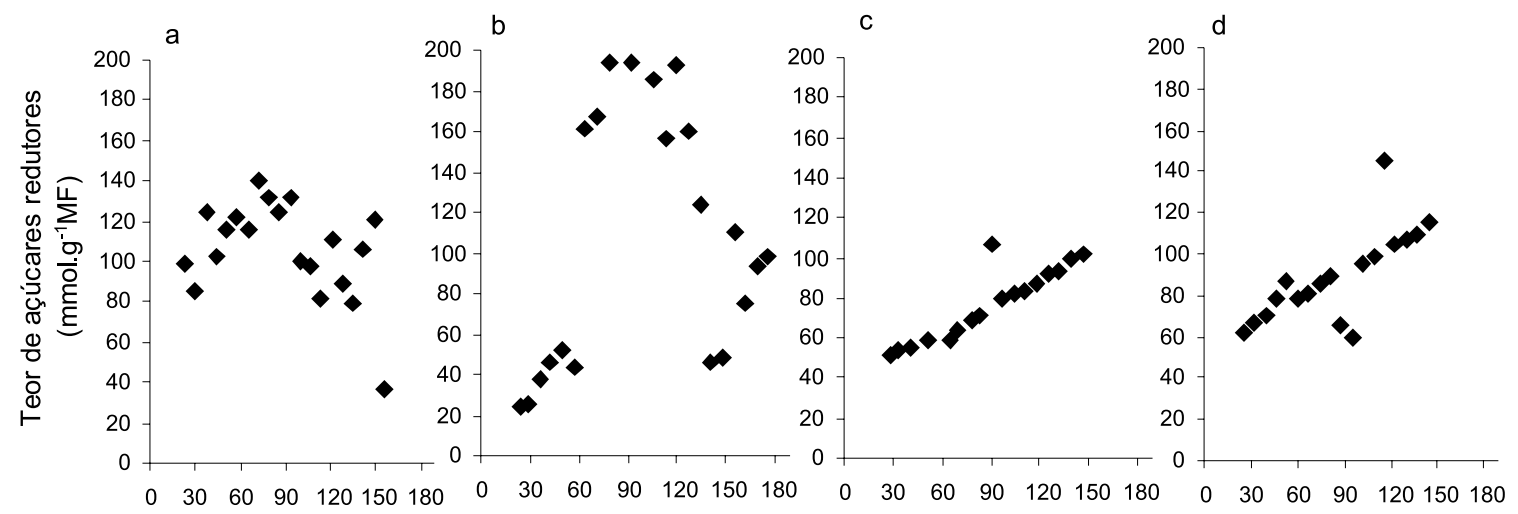

Dias após a poda

FIGURA 2 - Teor de açúcares redutores em folhas de videiras 'Syrah', durante os ciclos produtivos do (a) ciclo 1- primeiro semestre de 2003; (b) ciclo 2- segundo semestre de 2003; (c) ciclo 3- primeiro semestre de 2004; (d) ciclo 4- segundo semestre de 2004.

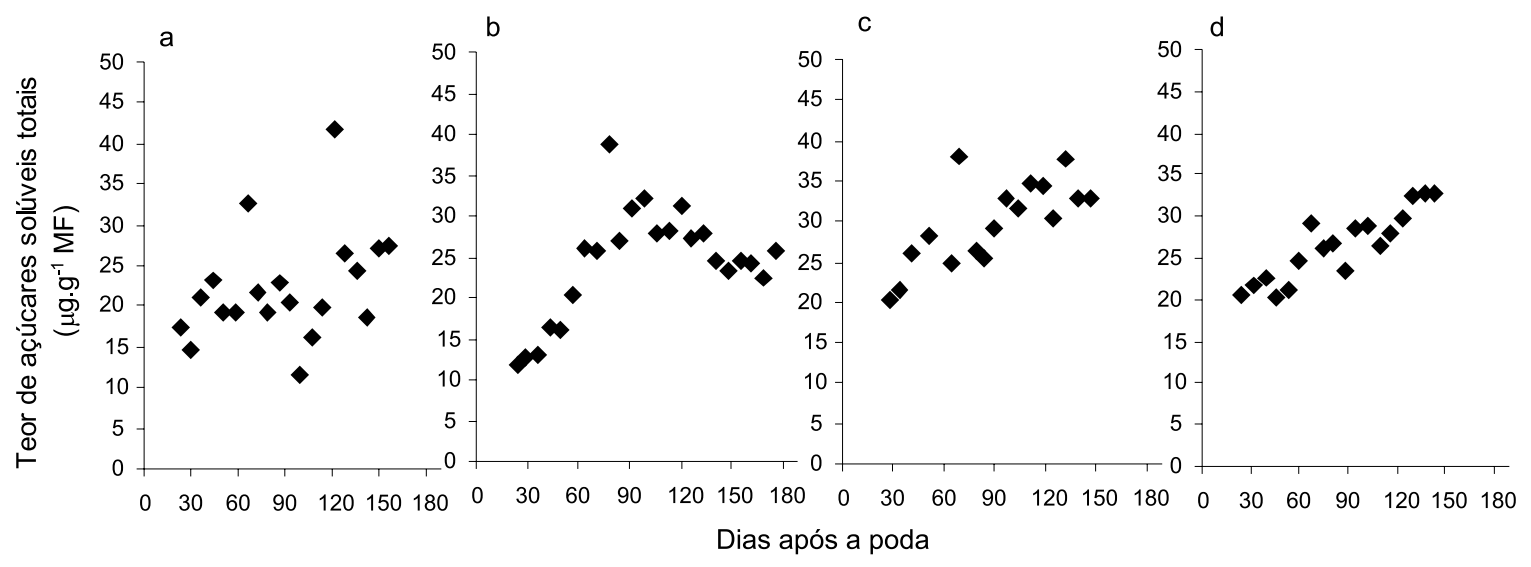

FIGURA 3 - Teor de açúcares solúveis totais em folhas de videiras 'Syrah', durante os ciclos produtivos do (a) ciclo 1- primeiro semestre de 2003; (b) ciclo 2- segundo semestre de 2003; (c) ciclo 3- primeiro semestre de 2004; (d) ciclo 4- segundo semestre de 2004 


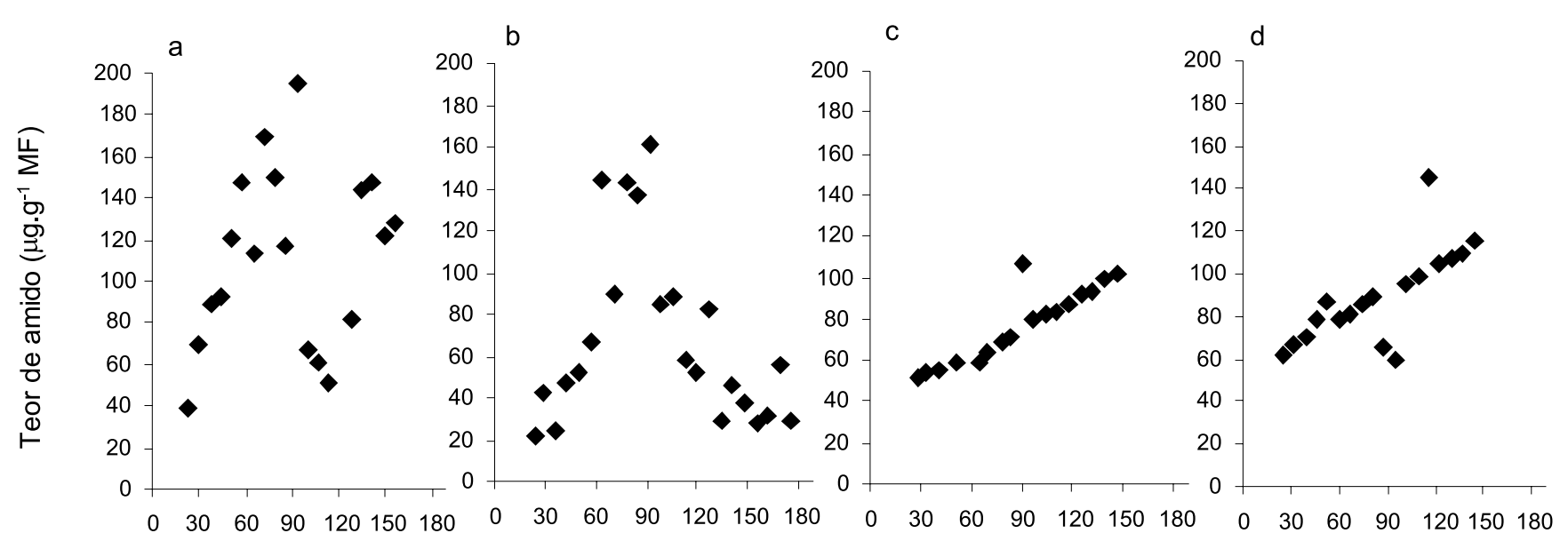

Dias após a poda

FIGURA 4 - Teor de amido em folhas de videiras 'Syrah', durante os ciclos produtivos do (a) ciclo 1- primeiro semestre de 2003; (b) ciclo 2- segundo semestre de 2003; (c) ciclo 3- primeiro semestre de 2004; (d) ciclo 4- segundo semestre de 2004.

TABELA 1 - Coeficientes de correlação entre variáveis climáticas e do metabolismo de carboidratos em folhas de videiras 'Syrah', durante os ciclos produtivos do primeiro semestre de 2003 (Ciclo 1- acima da linha pontilhada) e do segundo semestre de 2003 (Ciclo 2- abaixo da linha pontilhada). ns- não significativo; *- significativo a 5\% e **- significativo a $1 \%$.

\begin{tabular}{|c|c|c|c|c|c|c|c|c|c|}
\hline & DAP & $\mathrm{T}$ & TM & $\mathrm{Tm}$ & Ins & $\operatorname{Rad}$ & $\mathrm{Am}$ & AR & AST \\
\hline Dias ap & & $-0,4114 *$ & $-0,2817^{\mathrm{ns}}$ & $-0,4825^{*}$ & $0,13835^{\mathrm{ns}}$ & $-0,2305^{\mathrm{ns}}$ & $0,25291^{\mathrm{ns}}$ & $-0,3868^{\mathrm{ns}}$ & $0,35151^{\mathrm{ns}}$ \\
\hline Tempe & $0,85264 * *$ & & $0,77753^{* *}$ & $0,48625 *$ & $0,37815^{\mathrm{ns}}$ & $0,5077 *$ & $0,05979^{\text {ns }}$ & $0,30362^{\mathrm{ns}}$ & $0,31564^{\text {ns }}$ \\
\hline ima -TM & $0,8308^{* *}$ & $0,97934 * *$ & & $0,18539^{\mathrm{ns}}$ & $0,61129 * *$ & $0,68409 * *$ & $0,09167^{\mathrm{ns}}$ & $0,22135^{\mathrm{ns}}$ & $0,2671^{\text {ns }}$ \\
\hline Temp & $0,66789 * *$ & $0,86075 * *$ & $0,81948 * *$ & & $-0,1037^{\mathrm{ns}}$ & $0,05793^{\mathrm{ns}}$ & $0,21015^{\mathrm{ns}}$ & $0,60506^{* *}$ & $-0,0844^{\mathrm{ns}}$ \\
\hline Insola & $0,0529^{\text {ns }}$ & 0,25053 ns & $0,29567^{\mathrm{ns}}$ & $0,26301^{\mathrm{ns}}$ & & $0,83017 * *$ & $-0,0429^{\mathrm{ns}}$ & $0,02801^{\mathrm{ns}}$ & $0,12846^{\mathrm{ns}}$ \\
\hline Radia & $0,49099 *$ & $0,41793^{\mathrm{ns}}$ & $0,36758^{\mathrm{ns}}$ & $0,19518^{\mathrm{ns}}$ & $-0,6724 * *$ & & $0,03739^{\mathrm{ns}}$ & $0,20824^{\mathrm{ns}}$ & $-0,0118^{\mathrm{ns}}$ \\
\hline Amido-Am & $-0,077^{\mathrm{ns}}$ & $0,1924^{\mathrm{ns}}$ & $0,26451^{\mathrm{ns}}$ & $0,09489^{\mathrm{ns}}$ & $0,61432 * *$ & $-0,3182^{\text {ns }}$ & & $0,41193^{\mathrm{ns}}$ & $0,26815^{\text {ns }}$ \\
\hline Açúcares red & $0,25545^{\mathrm{ns}}$ & $0,35236^{\mathrm{ns}}$ & $0,37068^{\mathrm{ns}}$ & $0,13661^{\mathrm{ns}}$ & $-0,2467^{\mathrm{ns}}$ & 0,4557 * & 0,41000 & & $-0,0278^{\mathrm{ns}}$ \\
\hline Açúcares solúveis totais- AST & $0,35738^{\text {ns }}$ & $0,56591 * *$ & $0,63492 * *$ & $0,43438^{\mathrm{ns}}$ & $0,82361 * *$ & $-0,296^{\mathrm{ns}}$ & $0,77479 *$ &, $26375^{n}$ & \\
\hline
\end{tabular}

TABELA 2 - Coeficientes de correlação entre variáveis climáticas e do metabolismo de carboidratos em folhas de videiras 'Syrah', durante os ciclos produtivos do primeiro semestre de 2004 (Ciclo 3- acima da linha pontilhada) e do segundo semestre de 2004 (Ciclo 4- abaixo da linha pontilhada). ns- não significativo; *- significativo a 5\% e **-significativo a $1 \%$.

\begin{tabular}{|c|c|c|c|c|c|c|c|c|c|}
\hline & DAP & $\mathrm{T}$ & $\mathrm{TM}$ & $\mathrm{Tm}$ & Ins & $\operatorname{Rad}$ & $\mathrm{Am}$ & $\mathrm{AR}$ & AST \\
\hline Dias após a poda- DAP & & $-0,0789^{\text {ns }}$ & $0,21453^{\mathrm{ns}}$ & $-0,3970^{\mathrm{ns}}$ & $0,41813^{\mathrm{ns}}$ & $0,15025^{\mathrm{ns}}$ & $0,89960 * *$ & $0,86157 * *$ & $0,73096 * *$ \\
\hline ura média - $\mathrm{T}$ & $0,64714^{* *}$ & & $0,90211 * *$ & $0,49534 *$ & $0,30628^{\mathrm{ns}}$ & $0,32485^{\text {ns }}$ & $-0,1171^{\mathrm{ns}}$ & $-0,0829^{\mathrm{ns}}$ & $-0,1489^{\mathrm{ns}}$ \\
\hline xima -TM & $0,59627^{* *}$ & $0,88074 * *$ & & $0,26751^{\mathrm{ns}}$ & $0,47604^{\mathrm{ns}}$ & $0,41669^{\mathrm{ns}}$ & $0,13400^{\mathrm{ns}}$ & $0,12623^{\mathrm{ns}}$ & $-0,0229^{\mathrm{ns}}$ \\
\hline Tem & $0,07418^{\mathrm{ns}}$ & $0,63460 * *$ & $0,32185^{\text {ns }}$ & & $-0,1602^{\mathrm{ns}}$ & $-0,1148^{\mathrm{ns}}$ & $-0,4361^{\mathrm{ns}}$ & $-0,3964^{\mathrm{ns}}$ & $-0,2094^{\mathrm{ns}}$ \\
\hline Insol & $0,54874 *$ & $0,69106^{* *}$ & $0,81630 * *$ & $0,12288^{\text {ns }}$ & & $0,95038^{\mathrm{ns}}$ & $0,30860 *$ & $0,49435^{\mathrm{ns}}$ & $0,22645^{*}$ \\
\hline Radiac & $0,52272 *$ & $0,67411 * *$ & $0,71245 * *$ & $0,17817^{\text {ns }}$ & $0,87466^{* *}$ & & $0,06101^{\mathrm{ns}}$ & $0,28775^{\mathrm{ns}}$ & $0,07359^{\mathrm{ns}}$ \\
\hline Amido- Am & $0,73218^{* *}$ & $0,44998^{\mathrm{ns}}$ & $0,54119 *$ & $-0,0501^{\mathrm{ns}}$ & $0,45624^{\mathrm{ns}}$ & $0,37384^{\mathrm{ns}}$ & & $0,82779 * *$ & $0,61169 * *$ \\
\hline Açúc & $0,48385 *$ & $0,09451^{\mathrm{ns}}$ & $0,19006^{\mathrm{ns}}$ & $-0,1986^{\text {ns }}$ & $0,43712^{\mathrm{ns}}$ & $0,28334^{\text {ns }}$ & $0,43484^{\mathrm{ns}}$ & & 400 \\
\hline Açúcares solúveis totais- AST & $0,89814^{* *}$ & $0,67648 * *$ & $0,57445 *$ & $0,21226^{\text {ns }}$ & $0,47347 *$ & $0,41440^{\text {ns }}$ & $0,62272 * *$ & $0,41508^{\mathrm{ns}}$ & \\
\hline
\end{tabular}


TABELA 3 - Fases fenológicas e somas de graus-dia para os ciclos produtivos de videiras 'Syrah' avaliados. Petrolina, agosto/2005.

\begin{tabular}{|c|c|c|c|c|c|c|}
\hline \multirow{4}{*}{$\begin{array}{c}\text { Fases } \\
\text { fenológicas }\end{array}$} & \multicolumn{3}{|c|}{2003} & \multicolumn{3}{|c|}{2004} \\
\hline & \multicolumn{6}{|c|}{$1^{\circ}$ semestre } \\
\hline & \multicolumn{3}{|c|}{ Ciclo 1} & \multicolumn{3}{|c|}{ Ciclo 3} \\
\hline & Data & DAP & DPF & Data & DAP & DPF \\
\hline Poda pré-ciclo & 24/Dec/2002 & 0 & 0 & 09/Dec/2003 & 0 & 0 \\
\hline Florescimento & $22 / \mathrm{Jan} / 2003$ & 29 & 29 & $06 / \mathrm{Jan} / 2004$ & 28 & 28 \\
\hline Frutificação & $29 / \mathrm{Jan} / 2003$ & 36 & 7 & 19/Jan/2004 & 41 & 13 \\
\hline Pintor & 12/Mar/2003 & 78 & 42 & 29/Mar/2004 & 111 & 70 \\
\hline Colheita & $24 / \mathrm{Apr} / 2003$ & 121 & 43 & 14/Apr/2004 & 127 & 16 \\
\hline Poda & 08/Jun/2003 & 166 & 45 & 06/May/2004 & 149 & 22 \\
\hline \multirow{3}{*}{$\begin{array}{c}\text { Fases } \\
\text { fenológicas }\end{array}$} & \multicolumn{6}{|c|}{$2^{\circ}$ semestre } \\
\hline & \multicolumn{3}{|c|}{ Ciclo 2} & \multicolumn{3}{|c|}{ Ciclo 4} \\
\hline & Data & DAP & DPF & Data & DAP & DPF \\
\hline Poda pré-ciclo & $08 / \mathrm{Jun} / 2003$ & 0 & 0 & 06/May/2004 & 0 & 0 \\
\hline Florescimento & 21/Jul/2003 & 43 & 43 & 07/Jun/2004 & 32 & 32 \\
\hline Frutificação & 16/Aug/2003 & 69 & 26 & 21/Jun/2004 & 46 & 14 \\
\hline Pintor & $05 / \mathrm{Sep} / 2003$ & 89 & 20 & 16/Aug/2004 & 102 & 56 \\
\hline Colheita & 31/Oct/2003 & 145 & 56 & $04 / \mathrm{Sep} / 2004$ & 121 & 19 \\
\hline Poda & 09/Dec/2003 & 184 & 39 & $30 / \mathrm{Sep} / 2004$ & 147 & 26 \\
\hline
\end{tabular}

DAP:número de dias após a poda; DFF: duração da fase fenológica.

ocorre devido à alternância das temperaturas nesses períodos, pois são mais altas durante os meses de janeiro e fevereiro, início dos ciclos do $1^{\circ}$ semestre, e de outubro a dezembro, final dos ciclos do $2^{\circ}$ semestre.

Durante os ciclos do primeiro ano estudado (ciclos 1 e 2), os teores de AR nas folhas das videiras 'Syrah' aumentaram até o pintor e, após isso, decresceram (Figura 2a, b). Os ciclos do primeiro e segundo semestre de 2004 (ciclos 3 e 4, respectivamente) apresentam valores crescentes de teores de AR durante todo o ciclo produtivo (Figura 2c, d). Hunter et al. (1994) verificaram que o teor de glicose e frutose (AR) se intensificam, tanto em folhas basais como em apicais de videiras 'Müller-Thurgau' (Riesling x Silvaner), durante a maturação dos frutos, e diminuem ao final do ciclo produtivo, corroborando os resultados dos primeiros 2 ciclos deste trabalho.

De acordo com Takayanagi \& Yokotsuka (1997), o alto teor de AR nas folhas maduras, durante as fases iniciais do crescimento das bagas, se deve à alta taxa de transporte de fotoassimilados necessários à síntese de açúcares estruturais, como celulose, pectina e hemiceluloses. Além disso, há um grande acúmulo de glicose e frutose nas bagas durante a sua maturação. Esses autores ainda afirmam que a diminuição dos ARs foliares, após as bagas maduras (Figura 2a, b), ocorre devido à menor demanda por açúcares do cacho.

Antes do pintor, durante o crescimento dos frutos, houve um aumento nos teores foliares de AST no dois primeiros ciclos produtivos estudados. Após essa fase até a colheita dos cachos, as videiras apresentaram diferentes comportamentos para os dois ciclos de 2003, quanto aos teores foliares de AST. No ciclo 1, os ASTs foliares tiveram um decréscimo até alguns dias anteriores à colheita (Figura 3a). No ciclo 2, os teores foliares de AST diminuem do início da maturação até a poda aos 178 DAP (Figura 3b). De forma semelhante aos teores foliares de AR, há um aumento constante nos teores de AST durante os ciclos 3 e 4 (Figura 3c, d). Os ASTs são constituídos por todos os açúcares solúveis presentes nas folhas, entre os quais a sacarose ocorre em maior quantidade. De acordo com Hunter et al. (1994), os teores de sacarose têm comportamento inverso quando comparado aos
$\mathrm{AR}_{\mathrm{s}}$, concordando com os resultados obtidos para o $1^{\circ}$ ciclo deste trabalho (Figura 3a).

Durante o crescimento dos frutos e durante as fases de crescimento intenso dos ramos, devido a um grande transporte de açúcares das folhas para as bagas ou para os meristemas, o teor de amido nas folhas é baixo. Por outro lado, em fases em que não há grande transporte de açúcares das fontes (folhas fotossintetizantes) para os drenos (ramos e folhas em crescimento e frutos em maturação), como nas fases finais do ciclo produtivo, o amido tende a acumular nas folhas, regulando a atividade fotossintética (Pimentel, 1998). Neste experimento, o teor de amido nas folhas de 'Syrah' foi muito baixo no pegamento dos frutos,

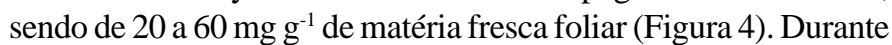
os ciclos 1 e 2, o teor de amido nas folhas aumentou durante o crescimento dos frutos e diminuiu após o pintor (Figuras $4 a, b$ ) Nos ciclos 3 e 4, ocorreu um aumento constante do teor de amido nas folhas (Figura 4c, d).

No início do ciclo 2, da poda até a frutificação, ocorreram temperaturas mínimas freqüentemente abaixo de $15^{\circ} \mathrm{C}$ e, em algumas ocasiões, abaixo de $12^{\circ} \mathrm{C}$. De acordo com Teixeira (2001), a temperatura média durante esse ciclo foi abaixo da média histórica da região, provocando uma diferença nas respostas metabólicas das videiras, em relação ao ciclo 1, que apresentou temperaturas mínimas, sempre acima de $15^{\circ} \mathrm{C}$, e freqüentemente em torno de $20^{\circ} \mathrm{C}$ e ao ciclo 4 , com temperaturas em torno de $15^{\circ} \mathrm{C}$ e sem temperaturas abaixo de $13^{\circ} \mathrm{C}$. Além das temperaturas mais baixas, os valores de radiação, durante o ciclo 2 , são inferiores a 400 ly. dia $^{-1}$, sendo, em média, inferiores aos demais ciclos.

Outro fator climático que influenciou no comportamento das videiras 'Syrah', ocorreu durante o ciclo 3. Nesse ciclo, entre 33 e 70 DAP, fases de formação e crescimento dos frutos, houve precipitação acima de $660 \mathrm{~mm}$ na região, maior que a média histórica anual de 1963 a 1999 de 567mm (Teixeira, 2001). Os valores de temperatura média e máxima, bem como de radiação e insolação durante esse período, são mais baixos em relação à mesma fase dos demais ciclos; devido a isso, a fase fenológica compreendida entre o início da frutificação e o início da maturação dos frutos é a mais longa e os teores foliares de AR, AST e amido são mais baixos em relação aos outros ciclos (Tabela 3, Figuras 2 - 4).

De acordo com Schiedeck et al. (1997), a temperatura influencia na velocidade dos processos metabólicos envolvidos na brotação, florescimento e pegamento dos frutos. Vários autores observaram que, tanto as condições climáticas, quanto as fases fenológicas, controlam a fotossíntese das videiras, influenciando, assim, na produção e no transporte de carboidratos (Hunter et al., 1994; Schier et al., 2000; Ferree et al., 2001; Dantas et al., 2003). Desta forma, a grande variação inter e intra-anual das condições climáticas provavelmente influenciaram nos teores de açúcares solúveis e insolúveis em folhas de 'Syrah' durante os ciclos produtivos estudados (Figuras 2 - 4).

\section{CONCLUSÕES}

1. Os açúcares solúveis e insolúveis são produzidos em maior quantidades a partir da quinta folha expandida e acumulamse em folhas próximas aos cachos. 
2. O acúmulo de açúcares nas folhas aumenta durante o início da maturação; no entanto, é fortemente influenciado pelas variações climáticas inter e intra-anuais.

\section{REFERÊNCIAS}

ALLEN, S.E.; GRIMSHAW, H.M.; PARKINSON, J.A.; QUARMBY, C. Chemical analys of ecological materials. Oxford: Blackwell Scientific, 1977. 127p.

DANTAS, B.F.; RIBEIRO, L.S. Variação intra-anual dos teores foliares de carboidratos e atividade de invertases em videiras no Vale do Rio São Francisco. Petrolina: Embrapa Semi-Árido, 2005. 22p.

DANTAS, B.F.; RIBEIRO, L.S.; SILVA, A.P.; LUZ, S.R.S Foliar carbohydrates content and invertase activity in vines at São Francisco River Valley - Brazil. Revista Brasileira de Fruticultura, Jaboticabal, v.27, n.2, p.198-202, 2005.

DANTAS, B.F.; RIBEIRO, L.S.; SILVA, A.P.; RIBEIRO, R.A.M.; LUZ, S.R.S. Atividades de invertases em folhas de videiras 'Petite Syrah' e 'Moscato Canelli' durante o período de formação. In: CONGRESSOBRASILEIRODE VITICULTURA E ENOLOGIA, 10., 2003, Bento Gonçalves. Anais... Bento Gonçalves: Embrapa Uva e Vinho, 2003, p.179.

FERREE, D.C.; MCARTNEY, S.J.; SCURLOCK, D.M. Influence of irradiance and period of exposure on fruit set of FrenchAmerican hybrid grapes. Journal of the American Society of Horticulture Science, Alexandria, v.126, n.3, p. 283-290, 2001.

HUNTER, J.J.; SKRIVAN, R.; RUFFNER, H.P. Diurnal and seasonal changes in leaves of Vitis vinifera $\mathrm{L}: \mathrm{CO}_{2}$ assimilation rates, sugar levels and sucrolitic enzyme activity. Vitis, Sielbeldingen, v.33, n.02, p. 189-195, 1994.

KLIEWER, W. M. Grapevine physiology: how does a grapevine make sugar? Berkeley: University of California, 1981. 13p.

MILLER, G.L. Use of dinitrosalicylis acid reagent for determination of reducing sugars. Analytical Chemistry, Washington, v.31, n.04, p.426-428, 1959.

MORRIS, D.L. Quantitative determiantion of carbohydrates with Drywood's anthrone reagent. Science, Washington, v.107, n.01, p.254-255, 1948.

PALLIOTTI, A.; CARTECHINI, A. Developmental changes in gas exchange activity in flowers, berries and trendils of fieldgrown Cabernet Sauvignon. American Journal of Enology and Viticulture, Davis, v.54, n. 4, p.317-323, 2001.

PIMENTEL, C. Metabolismo de carbono na agricultura tropical. Seropédica: Edur, 1998. 150p.

POMMER, C.V.; PASSOS, I.R. Fisiologia da videira: como produz açúcar uma videira. Disponível em: <http:// u s e r s.d i r e c t n e t . c o m . b r / p o m m e r / COMOPRODUZACUCAR.pdf >. Acesso em : jul03 jun 2005.

ROITSCH, T.; BALIBREA, M.E.; HOFMANN, M.; PROELS, R.; SINHA, A.K. Extracellular invertases: metabolic enzyme and metabolic protein. Journal of Experimental Botany, Lancaster, v.54, n.382, p. 513-524, 2003.
ROITSCH, T.; EHNE $\beta$, R.; GOETZ, M.; HOUSE, B.; HOFMANN, M; SINHA, A.K. Regulation and function of extracellular invertase from higher plants in relation to assimilate partitioning, stress response and sugar signalling. Australian Journal of Plant Physiology, Collingwood, v.27, n.09, p. 815-825, 2000 .

SCHIEDECK, G.; MIELE, A.; BARRADAS, C I N; MANDELLI, F. Fenologia da videira Niágara Rosada cultivada em estufa e a céu aberto. Revista Brasileira de Agrometeorologia, Santa Maria, v. 5, n. 2, p. 199-206, 1997.

SCHIER, A.A.; HOFFMANN-THOMA, G.; VAN BEL, A.J.E. Temperature effects on symplasmic and apoplasmic phloem loading and loading-associated carbohydrate processing. Australian Journal of Plant Physiology, Collingwood, v.27, n.9, p.769-778, 2000.

TAKAYANAGI, ,T. \& YOKOTSUKA, K. Relationship between sucrose accumulation and sucrose-metabolizng enzymes in developing grapes. American Journal of Enology and Viticulture. Davis, v.48, n.4, p-403-407, 1997.

TEIXEIRA, A.H.C. Informações agrometeorológicas do Pólo Petrolina-PE/Juazeiro-BA. Petrolina: Embrapa Semi-Árido, 2001.48p.

TYMOWSKA-LALANNE, Z.; KREIS, M. The plant invertases: physiology, biochemistry and molecular biology. Advances in Botanical Research. Cambridge, v.28, n. 1, p.71-117, 1998.

YEMM, E.W.; WILLIS,A.J. The estimation of carbohydrates in plants extracts by anthrone. Biochemical Journal. Colchester. v. 57, n.5, p.508-514, 1954. 